\title{
THE SOUTHERN AFRICAN INSTITUTE OF MINING AND METALLURGY
} WESTERN CAPE BRANCH

ANNUAL FINANCIAL STATEMENTS

FOR THE YEAR ENDED 30 JUNE 2019 
The SAIMM Western Cape Branch

Annual Financial Statements for the year ended 30 June 2019

\section{General Information}

\section{Country of incorporation and domicile}

Nature of business and principal activities

Office Bearers

Registered office

Auditors

Preparer

Postal address

\section{South Africa}

The Southern African Institute of Mining and Metallurgy is a professional institute with local and international links aimed at assisting members to source information about technological developments in the mining, metallurgy, and related sectors. This non-profit entity operates in South Africa.

Professor S. Ndlovu

A.S. Macfarlane

M.I. Mthenjane

Z. Botha

I.J. Geldenhuys

V.G. Duke

Professor R.T. Jones

University of Cape Town

Private Bag X3

Rondebosch

7701

PO Box 61127

Marshalltown

2107

Standard Bank of South Africa

Genesis Chartered Accountants

Chartered Accountants (SA)

Registered Auditors

The annual financial statements were independently compiled by:

J. Den Drijver CA(SA) 


\section{The SAIMM Western Cape Branch}

Annual Financial Statements for the year ended 30 June 2019

\section{Index}

The reports and statements set out below comprise the annual financial statements presented to the Office Bearers:

Office Bearers' Responsibilities and Approval

Office Bearers' Report

Independent Auditor's Report

Statement of Financial Position

Statement of Comprehensive Income

Statement of Changes in Equity

Statement of Cash Flows

Accounting Policies

Notes to the Annual Financial Statements

The following supplementary information does not form part of the annual financial statements and is unaudited: Detailed Income Statement 


\section{Office Bearers' responsibilities and approval}

The Office Bearers are required to maintain adequate accounting records and are responsible for the content and integrity of the annual financial statements and related financial information included in this report. It is their responsibility to ensure that the annual financial statements fairly present the state of affairs of The Southern African Institute of Mining and Metallurgy Western Cape Branch as at the end of the financial year and the results of its operations and cash flows for the period then ended, in conformity with the International Financial Reporting Standard for Small and Medium-sized Entities. The external auditors are engaged to express an independent opinion on the annual financial statements.

The annual financial statements are prepared in accordance with the International Financial Reporting Standard for Small and Mediumsized Entities and are based upon appropriate accounting policies consistently applied and supported by reasonable and prudent judgements and estimates.

The Office Bearers acknowledge that they are ultimately responsible for the system of internal financial control established by the Branch and place considerable importance on maintaining a strong control environment. To enable the Office Bearers to meet these responsibilities, the Office Bearers sets standards for internal control aimed at reducing the risk of error or loss in a cost effective manner. The standards include the proper delegation of responsibilities within a clearly defined framework, effective accounting procedures and adequate segregation of duties to ensure an acceptable level of risk. These controls are monitored throughout the Branch and all employees are required to maintain the highest ethical standards in ensuring the Branch's business is conducted in a manner that in all reasonable circumstances is above reproach. The focus of risk management in the Branch is on identifying, assessing, managing and monitoring all known forms of risk across the Branch. While operating risk cannot be fully eliminated, the branch endeavours to minimize it by ensuring that appropriate infrastructure, controls, systems and ethical behaviour are applied and managed within predetermined procedures and constraints.

The Office Bearers are of the opinion, based on the information and explanations given by management, that the system of internal control provides reasonable assurance that the financial records may be relied on for the preparation of the annual financial statements. However, any system of internal financial control can provide only reasonable, and not absolute, assurance against material misstatement or loss.

The Office Bearers have reviewed the Institute's cash flow forecast for the year to 30 June 2020 and, in the light of this review and the current financial position, they are satisfied that the Branch has or has access to adequate resources to continue in operational existence for the foreseeable future.

The external auditors are responsible for independently auditing and reporting on the Institute's annual financial statements. The annual financial statements have been examined by the Branch's external auditors and their report is presented on pages 764-765.

The annual financial statements set out on pages 766-770, which have been prepared on the going concern basis, were approved by the Office Bearers on 13 August 2019 and are signed on their behalf by:

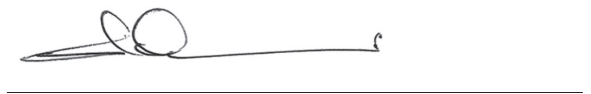

A.S. Macfarlane

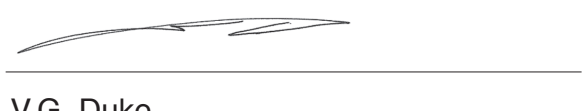

V.G. Duke 


\section{The SAIMM Western Cape Branch}

Annual Financial Statements for the year ended 30 June 2019

\section{Office Bearers' Report}

The Office Bearers have pleasure in submitting their report on the annual financial statements of The Southern African Institute of Mining and Metallurgy Western Cape Branch for the year ended 30 June 2019.

\section{Nature of business}

The Southern African Institute of Mining and Metallurgy is a professional institute with local and international links aimed at assisting members to source information about technological developments in the mining, metallurgy, and related sectors.

There have been no material changes to the nature of the company's business from the prior year.

\section{Review of financial results and activities}

The annual financial statements have been prepared in accordance with International Financial Reporting Standard for Small and Medium-sized Entities and the accounting policies for this Institute. The accounting policies have been applied consistently compared to the prior year.

Full details of the financial position, results of operations and cash flows of the Southern African Institute of Mining and Metallurgy Western Cape branch are set out in these annual financial statements.

\section{Office Bearers}

The Office Bearers in office at the date of this report are as follows:

\section{Office Bearers}

\section{A.S. Macfarlane \\ M.I. Mthenjane \\ Z. Botha \\ I.J. Geldenhuys}

Professor S. Ndlovu

V.G. Duke

Professor R.T. Jones

There have been no changes to the abovementioned structure for the period under review.

\section{Events after the reporting period}

The Office Bearers are not aware of any material event which occurred after the reporting date and up to the date of this report.

\section{Going concern}

The Office Bearers believe that the Branch has adequate financial resources to continue in operation for the foreseeable future and accordingly the annual financial statements have been prepared on a going concern basis. The Office Bearers have satisfied themselves that the Branch is in a sound financial position and that it has access to sufficient borrowing facilities to meet its foreseeable cash requirements. The Office Bearers are not aware of any new material changes that may adversely impact the Branch. The Office Bearers are also not aware of any material noncompliance with statutory or regulatory requirements or of any pending changes to legislation which may affect the Branch.

\section{Auditors}

Genesis Chartered Accountants will continue in office. 


\section{Independent Auditor's Report}

To the Office Bearers of The Southern African Institute of Mining and Metallurgy Western Cape Branch.

\section{Opinion}

We have audited the annual financial statements of The Southern African Institute of Mining and Metallurgy Western Cape Branch (the Branch) set out on pages 766-769, which comprise the statement of financial position as at 30 June 2019, and the statement of comprehensive income, statement of changes in equity and statement of cash flows for the year then ended, and notes to the annual financial statements, including a summary of significant accounting policies.

In our opinion, the annual financial statements present fairly, in all material respects, the financial position of The Southern African Institute of Mining and Metallurgy Western Cape Branch as at 30 June 2019, and its financial performance and cash flows for the year then ended in accordance with International Financial Reporting Standard for Small and Medium -sized Entities and the requirements of the Companies Act 71 of 2008.

\section{Basis for opinion}

We conducted our audit in accordance with International Standards on Auditing. Our responsibilities under those standards are further described in the Auditor's Responsibilities for the Audit of the annual financial statements section of our report. We are independent of the company in accordance with the sections 290 and 291 of the Independent Regulatory Board for Auditors' Code of Professional Conduct for Registered Auditors (Revised January 2018), parts 1 and 3 of the Independent Regulatory Board for Auditors' Code of Professional Conduct for Registered Auditors (Revised November 2018) (together the IRBA Codes) and other independence requirements applicable to performing audits of annual financial statements in South Africa. We have fulfilled our other ethical responsibilities, as applicable, in accordance with the IRBA Codes and in accordance with other ethical requirements applicable to performing audits in South Africa. The IRBA Codes are consistent with the International Ethics Standards Board for Accountants' Code of Ethics for Professional Accountants and the International Ethics Standards Board for Accountants' International Code of Ethics for Professional Accountants (including International Independence Standards) respectively. We believe that the audit evidence we have obtained is sufficient and appropriate to provide a basis for our opinion.

\section{Other information}

The Office Bearers are responsible for the other information. The other information comprises the information included in the document titled 'The Southern African Institute of Mining and Metallurgy Western Cape Branch annual financial statements for the year ended 30 June 2019', which includes the Office Bearers' Report as required by the Companies Act 71 of 2008 and the Detailed Income Statement, which we obtained prior to the date of this report. The other information does not include the annual financial statements and our auditor's report thereon.

Our opinion on the annual financial statements does not cover the other information and we do not express an audit opinion or any form of assurance conclusion thereon.

In connection with our audit of the annual financial statements, our responsibility is to read the other information and, in doing so, consider whether the other information is materially inconsistent with the annual financial statements or our knowledge obtained in the audit, or otherwise appears to be materially misstated. If, based on the work we have performed on the other information obtained prior to the date of this auditor's report, we conclude that there is a material misstatement of this other information, we are required to report that fact. We have nothing to report in this regard.

\section{Responsibilities of the Office Bearers for the Annual Financial Statements}

The Office Bearers are responsible for the preparation and fair presentation of the annual financial statements in accordance with International Financial Reporting Standard for Small and Medium-sized Entities and the requirements of the Companies Act 71 of 2008 , and for such internal control as the office bearers determine is necessary to enable the preparation of annual financial statements that are free from material misstatement, whether due to fraud or error.

In preparing the annual financial statements, the Office Bearers are responsible for assessing the Branch's ability to continue as a going concern, disclosing, as applicable, matters related to going concern and using the going concern basis of accounting unless the office Bearers either intend to liquidate the branch or to cease operations, or have no realistic alternative but to do so. 


\section{Independent Auditor's Report}

\section{Auditor's responsibilities for the audit of the Annual Financial Statements}

Our objectives are to obtain reasonable assurance about whether the annual financial statements as a whole are free from material misstatement, whether due to fraud or error, and to issue an auditor's report that includes our opinion. Reasonable assurance is a high level of assurance, but is not a guarantee that an audit conducted in accordance with International Standards on Auditing will always detect a material misstatement when it exists. Misstatements can arise from fraud or error and are considered material if, individually or in the aggregate, they could reasonably be expected to influence the economic decisions of users taken on the basis of these annual financial statements.

As part of an audit in accordance with International Standards on Auditing, we exercise professional judgement and maintain professional scepticism throughout the audit. We also:

- Identify and assess the risks of material misstatement of the annual financial statements, whether due to fraud or error, design and perform audit procedures responsive to those risks, and obtain audit evidence that is sufficient and appropriate to provide a basis for our opinion. The risk of not detecting a material misstatement resulting from fraud is higher than for one resulting from error, as fraud may involve collusion, forgery, intentional omissions, misrepresentations, or the override of internal control.

- Obtain an understanding of internal control relevant to the audit in order to design audit procedures that are appropriate in the circumstances, but not for the purpose of expressing an opinion on the effectiveness of the company's internal control.

- Evaluate the appropriateness of accounting policies used and the reasonableness of accounting estimates and related disclosures made by the directors.

- Conclude on the appropriateness of the Office Bearers' use of the going concern basis of accounting and based on the audit evidence obtained, whether a material uncertainty exists related to events or conditions that may cast significant doubt on the company's ability to continue as a going concern. If we conclude that a material uncertainty exists, we are required to draw attention in our auditor's report to the related disclosures in the annual financial statements or, if such disclosures are inadequate, to modify our opinion. Our conclusions are based on the audit evidence obtained up to the date of our auditor's report. However, future events-or conditions may cause the company to cease to continue as a going concern.

- Evaluate the overall presentation, structure and content of the annual financial statements, including the disclosures, and whether the annual financial statements represent the underlying transactions and events in a manner that achieves fair presentation.

We communicate with the directors regarding, among other matters, the planned scope and timing of the audit and significant audit findings, including any significant deficiencies in internal control that we identify during our audit.

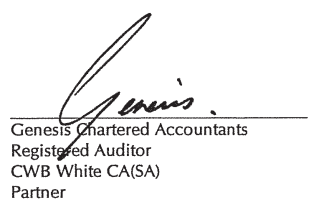




\section{Statement of Financial Position as at $\mathbf{3 0}$ June 2019}

Assets

Non-Current Assets

Other financial assets

2

705028

683156

\section{Current Assets}

Trade and other receivables

3

311

18462

Cash and cash equivalents

4

548657

558313

\begin{tabular}{lrrr}
\hline & 548968 & 576775 \\
\hline Total Assets & 1253996 & 1259931 \\
\hline
\end{tabular}

Equity and Liabilites

Equity

Accumulated Funds

Liabilites

Current Liabilities

Trade and other payables

5

99899

104322

Total Equity and Liabilities

1253996

1259931

\section{Statement of Comprehensive Income}

\begin{tabular}{|c|c|c|c|}
\hline & Note(s) & $\begin{array}{c}2019 \\
\mathrm{R}\end{array}$ & $\begin{array}{c}2018 \\
\mathrm{R}\end{array}$ \\
\hline Revenue & 6 & - & 178700 \\
\hline Cost of sales & & - & (190 390) \\
\hline Gross loss & & - & $(11690)$ \\
\hline Other income & 7 & - & 223351 \\
\hline Operating expenses & & $(48521)$ & (17 933) \\
\hline Operating loss (profit) & & $(48521)$ & 193728 \\
\hline Investment revenue & 8 & 25137 & 21729 \\
\hline Fair value adjustmments & & 21872 & 86220 \\
\hline (Loss) profit for the year & & $(1512)$ & 301677 \\
\hline
\end{tabular}




\section{Statement of Changes in Equity}

Accumulated Funds

$\mathrm{R}$

853032

Balance at 1 July 2017

Profit for the year

Balance at 1 July 2018

Loss for the year

Balance at 30 June 2019

\section{Statement of Cash Flows}

$\begin{array}{ccc}\text { Note(S) } & 2019 & 2018 \\ \mathrm{R} & \mathrm{R}\end{array}$

Cash flows from operating activities

Cash (used in) generated from operations

9

Interest income

Net cash from operating activities

Cash flows from investing activities

Decrease in financial assets

Net cash from investing activities

Cash flows from financing activities

Repayment of other financial liabilities

21872

(137 131)

Net cash from financing activities

21872

Total cash movement for the year 


\section{The SAIMM Western Cape Branch}

Annual Financial Statements for the year ended 30 June 2019

\section{Accounting Policies}

\section{Basis of preparation and summary of significant accounting policies}

The annual financial statements have been prepared on a going concern basis in accordance with the International Financial Reporting Standard for Small and Medium-sized Entities. The annual financial statements have been prepared on the historical cost basis, and incorporate the principal accounting policies set out below. They are presented in South African rands.

These accounting policies are consistent with the previous period.

\subsection{Significant judgements and sources of estimation uncertainty Critical judgements in applying accounting policies}

The Office Bearers did not make critical judgements in the application of accounting policies, apart from those involving estimations, which would significantly affect the annual financial statements.

\section{Key sources of estimation uncertainty}

The financial statements do not include assets or liabilities whose carrying amounts were determined based on estimations for which there is a significant risk of material adjustments in the following financial year as a result of the key estimation assumptions.

\subsection{Financial instruments \\ Initial measurement}

Financial instruments are initially measured at the transaction price (including transaction costs except in the initial measurement of financial assets and liabilities that are measured at fair value through profit or loss) unless the arrangement constitutes, in effect, a financing transaction in which case it is measured at the present value of the future payments discounted at a market rate of interest for a similar debt instrument.

\section{Financial instruments at fair value}

All other financial instruments, including equity instruments that are publicly traded or whose fair value can otherwise be measured reliably, without undue cost or effort, are measured at fair value through profit and loss.

If a reliable measure of fair value is no longer available without undue cost or effort, then the fair value at the last date that such a reliable measure was available is treated as the cost of the instrument. The instrument is then measured at cost less impairment until management are able to measure fair value without undue cost or effort.

\subsection{Impairment of assets}

The Branch assesses at each reporting date whether there is any indication that property, plant and equipment or intangible assets or goodwill may be impaired.

If there is any such indication, the recoverable amount of any affected asset (or group of related assets) is estimated and compared with its carrying amount. If the estimated recoverable amount is lower, the carrying amount is reduced to its estimated recoverable amount, and an impairment loss is recognized immediately in profit or loss.

If an impairment loss subsequently reverses, the carrying amount of the asset (or group of related assets) is increased to the revised estimate of its recoverable amount, but not in excess of the amount that would have been determined had no impairment loss been recognized for the asset (or group of assets) in prior years. A reversal of impairment is recognized immediately in profit or loss.

\subsection{Revenue}

Revenue is recognized to the extent that the Branch has transferred the significant risks and rewards of ownership of goods to the buyer, or has rendered services under an agreement provided the amount of revenue can be measured reliably and it is probable that economic benefits associated with the transaction will flow to the Branch. Revenue is measured at the fair value of the consideration received or receivable, excluding sales taxes and discounts.

Interest is recognized, in profit or loss, using the effective interest rate method. 


\section{Notes to the Annual Financial Statements}

2. Other financial assets

At fair value

Listed shares

Non-current assets

At fair value

3. Trade and other receivables

Trade receivables

UCT Fund

\section{Cash and cash equivalents}

Cash and cash equivalents consist of:

Bank balances

Short-term deposits

\section{Other financial liabilities}

Trade debtors in credit

UCT fund

Accruals

Accrued audit fees

Acrued audit fees

$-$

\section{Revenue}

Rendering of services

\section{Other income}

Write-off of loan account

\section{Investment revenue} Interest revenue

Bank

9. Cash (used in) generated from operations

Loss before taxation

Adjustment for:

Interest received

Fair value adjustments

Changes in working capital

Trade and other receivables

Trade and other payables 


\section{Detailed Income Statements}

Notes

2019

$\mathrm{R}$
2018

$\mathrm{R}$

Revenue

Conference fees

Cost of sales

Conference costs

(190 390)

Gross loss

(11 690)

Other income

Write-off of loan account

Fair value adjustments

86220

Interest received

8

21872

21729

47009

\section{Operating expenses}

AGM expenses

10430

850

Bad debts

18463

Bank charges

1746

Catering - Meetings

2864

Committee dinner

7714

Computer expenses

Printing and stationery

Reviewer's remuneration

Subscriptions

Student evenings

Telephone and fax

304

\section{Erratum}

It has come to our attention that some text in the Contents page in the SAIMM Journal vol. 119, no. 7 was omitted. 'Optimization of the cycle time to increase productivity at Ruashi Mining, by I.N.M. Nday and H. Thomas' should have been listed.

We apologise to the authors for this oversight. 